\title{
THE DESIGN OF THE DESIGN BRIEF: AN ANALYSIS OF BRAZILIAN, JAPANESE AND TURKISH STUDENTS
}

\author{
Nicele BRANDA ${ }^{1}$, Leandro SILVEIRA ${ }^{1}$, Julio VAN DER LINDEN ${ }^{1}$, Erik BOHEMIA ${ }^{2}$ and \\ Pinar KAYGAN ${ }^{3}$ \\ ${ }^{1}$ Universidade Federal do Rio Grande do Sul - UFRGS \\ ${ }^{2}$ Academy of Design Innovation Management - ADIM \\ ${ }^{3}$ Middle East Technical University - METU
}

\begin{abstract}
This study addresses the strategies used by students to develop a design brief during the 2018 edition of the Global Studio, a cross-institutional project. In the Global Studio, students from different universities around the world work in paired teams simultaneously as clients and designers. In 2018, the theme was "local mobilities", challenging design students to propose a solution for a local problem presented by their counterparts. Then the teams were asked to define an initial problem and prepare their design brief. This process involved common design activities and techniques such as contextual research, desktop research, and problem definition. The design briefs were published at their counterparts' blogs and analysed before the teams started their work as designers. Three teams from Brazil, worked with two teams from Turkey and one team from Japan. The analysis of how these students designed their design brief was the main objective of this study. The study adopted the following methods: observations, document analysis and interviews. Results demonstrated different levels of expertise and experience across teams. They suggest that strategies employed are associated both to individual backgrounds and to institutional effects.
\end{abstract}

Keywords: Design brief, global studio, collaborative project

\section{INTRODUCTION}

Determining the route to find a solution in a product, process or service - an essential function of the design brief that the designer must carry out to meet customer expectations - is not exhausted by meeting a list of specifications. In the design activity, due to its nature and methodologies, a design brief is considered a fundamental step. Briefing is not just presenting a set of documents to the design team; it is a process of developing a deep understanding of client needs [1]. The necessary communication for true understanding is affected by culture, language (and the difficulties of translation) and the challenges of using the respective methodologies or tools. Furthermore, the effort can be wasted by specificities such as the different backgrounds of the teams and their individualities, which may lead to a lack of understanding of the desires and needs (often poorly expressed by the user) to be met. Among the abovementioned difficulties in the creation of a brief design, the main limitations are the gaps in the designers' training in the user-focused design approach [1], which leads to a detachment from the real user and results in superficial specifications that fail to meet the user's demands. Although it is defined specifically at the initial moment of the work, the design brief presents itself in different ways throughout the project. In the pre-project stage, the brief can be seen as the agreement reached among the parties involved. In the project stage, it functions as the roadmap to be followed during development, defining the intermediate stages. Finally, it can also be used as a monitoring and evaluation tool. In the postproject stage, "one can check whether the results achieved were satisfactory and if all the expected aspects were actually achieved"[2].

This paper reports on the initial stage of projects developed during the 2018 edition of the Global Studio Project, a multi-institutional and cross-cultural project [3]. The Global Studio unequivocally represents a contemporary society, with geographically distributed teams of clients or designers and natural difficulties of time zones. On the one hand, it provides the participating students with valuable 
experiences. On the other hand, it suffers from the inexperience of these same students, still in academic formation. As a premise, the Global Studio provides a learning environment that prepares students to work on projects through virtual partnerships, in a non-linear and non-hierarchical model. During the collaborative project, students play dual roles, working both as clients and as designers. Located in different countries, the teams communicate over the internet and post the results of their ongoing work on blogs so that the team in the role of client can suggest modifications based on their effective needs and particularities. In the role of clients, they commission one of the other teams to design a design solution. As designers, they are commissioned by that same team to design a solution to a local problem while meeting their clients' needs. In this way, students are intended to be autonomous in all stages of the project, since professional life requires them to be flexible and confident in their initiatives. In addition, they are challenged to deal with different cultural contexts.

In this context, this article presents an analysis of how these students designed their design brief. It seeks to understand to what extent and in which ways the design brief guided the development of cross-cultural projects. Thus, it seeks to answer the following question: how did the subjects approached in the design brief guide the development of the projects on urban mobility by the teams from Brazil, Japan and Turkey in the 2018 Global Studio?

\section{RESEARCH METHODOLOGY}

This study is of qualitative nature. The data used in this study comes from three main sources: $i$. observation of the activities performed by the Brazilian teams in class; ii. the blog posts and comments written by the participating teams on their own blogs and on their paired teams' blogs; and iii. interviews carried out with the Brazilian teams at the end of the project.

The notes taken during the class observations enabled a narrative account of the activities to further the understanding of how the design brief process was carried out by the different teams involved. This narrative analysis was complemented by the content analysis of the blog posts and comments made by the participating team and their counterparts. The blog content was analysed according to four dimensions of the design brief: cultural context, urban space, mobility and user behaviour. The interactions were checked for the presence or absence of these four dimensions. Finally, the qualitative analysis of the interviews evidenced the perceptions and the challenges faced by the teams in a multicultural context.

\section{THE DESIGN BRIEF DEVELOPMENT AT GLOBAL STUDIO 2018}

The 2018 edition of the Global Studio included 16 teams of students from five universities - two from Brazil and one from Italy, Japan and Turkey each. At one of the Brazilian universities, the meetings were accompanied by students from the Design Graduate Program: master's students in the role of tutors and $\mathrm{PhD}$ students in the role of observers. This study addresses the processes used by this university's teams and their peers (Table 1).

- $\quad$ Team 5 (3 students from Turkey) paired with Team 11 (3 students from Brazil)

- Team 6 (3 students from Turkey) paired with Team 12 (3 students from Brazil)

- Team 14 (9 students from Japan) paired with Team 16 (2 students from Brazil)

The first stage consisted in the presentation of the project; in the second week, the development of the detailed design brief began. As a reminder to students, blog posts on how design briefs could be conceived were written. These posts listed the expected qualities of the project's outcome and the constraints to be considered, such as international standards, production methods, materials, and storage requirements. It was stated that those constraints should not restrict how to achieve those qualities. In this orientation to students, a basic checklist of design briefs was also presented. The checklist included: project overview and history; user and target market; design requirements; and the schedule. Subsequently, the students published the first presentations (texts, sketches and/or movies) on their peer groups' blogs in order to discuss with the peer team the issues related to the chosen topic. The reports were posted on the blogs, along with the photos taken during the process. The process lasted for two weeks, involving different strategies and levels of commitment. At the end, each set of paired teams was requested to reach an agreed design brief. This process involved common design activities and techniques such as contextual research, desktop research, and problem definition.

For all teams the design brief stage started with discussion of how to propose a brief design, followed by research on the design theme. Subsequently, the students published on their peer group's blogs the first presentations (texts, sketches and/or movies) in order to discuss with the peer team, the issues 
related to the chosen topic. The reports were made in the blogs, as well as the photos that present in the process. It lasted for two weeks, involving different strategies and levels of commitment, and at the end each set of paired teams was requested to reach an agreed design brief.

\section{RESULTS AND DISCUSSION}

\subsection{Observation of the activities developed by the Brazilian teams in class}

During the development of the design brief, two doctoral students observed the activities developed by Team 11, Team 12 and Team 16. All teams were expected to attend the classes, during which they would work on their assigned project under the supervision of a pair of tutors comprised of master's students. However, sometimes one of the teams failed to attend the class, affecting observations. In all teams, the design brief stage started with a discussion on how to propose a brief design, followed by research on the design theme. When playing the role of clients, the students developed the problem to be solved by the paired team, as shown in the flowchart in Figure 1.

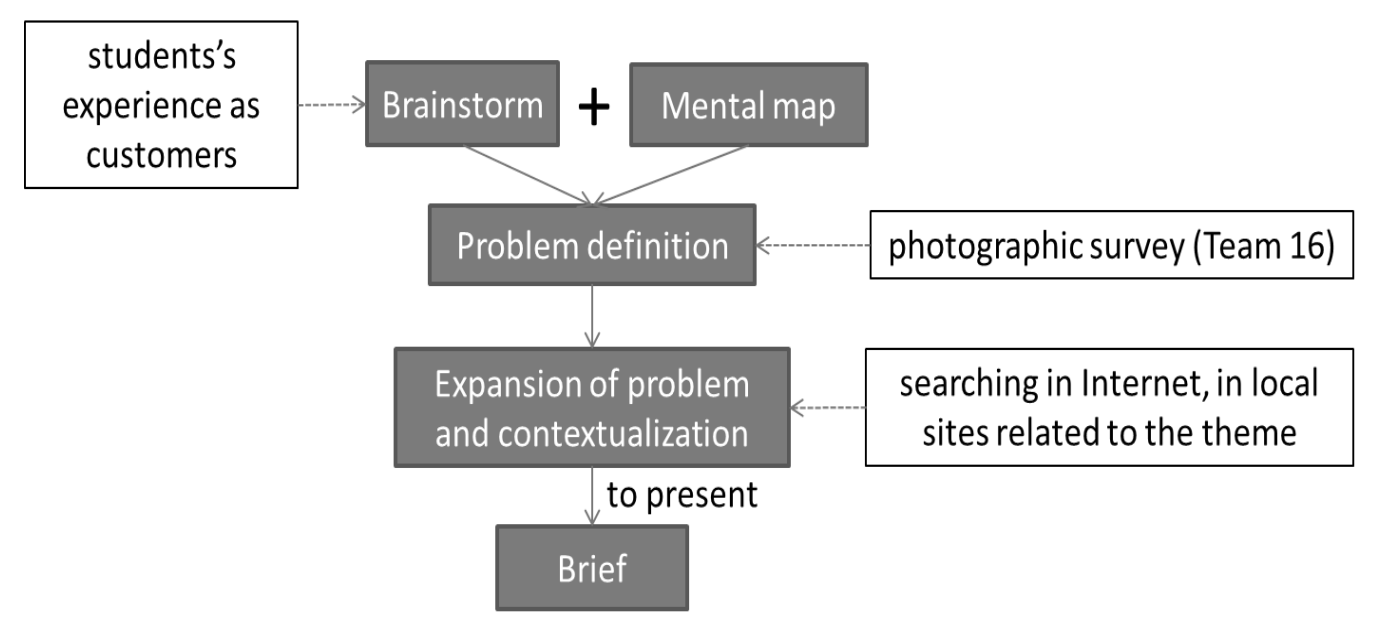

Figure 1. General flowchart used by Teams 11, 12 and 16 working as clients

Observations allowed to verify how the teams, working as designers, took into account cultural differences, as presented in the flowchart shown in Figure 2.

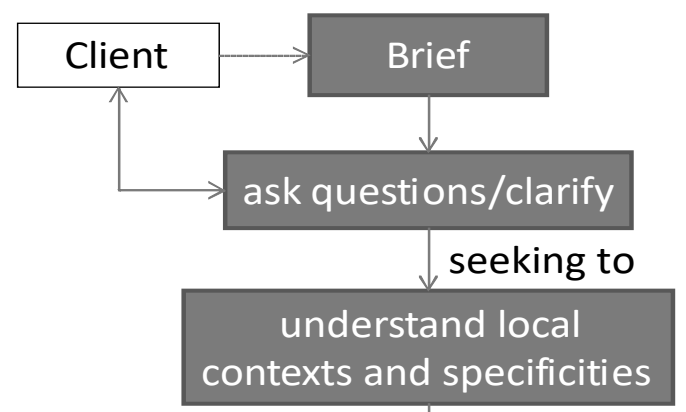

to present

Project

Figure 2. Students (Team 11, 12 and 16) as designers

\subsection{Analysis of all teams' posts on their blogs and on their paired teams' blogs}

Blog monitoring was performed during the design brief process, throughout the project and after the presentation of the project. This procedure was adopted in order to identify any mention about the design brief. In the consecutive stages, some gaps that persisted in the initial stage were fulfilled. Doubts about details could be elucidated when the brief design had covered all the topics from the beginning. In order 
to guide blog analysis, a framework with four dimensions was conceived (Figure 3). It was used as a basis to identify which dimensions were considered by each of the teams.

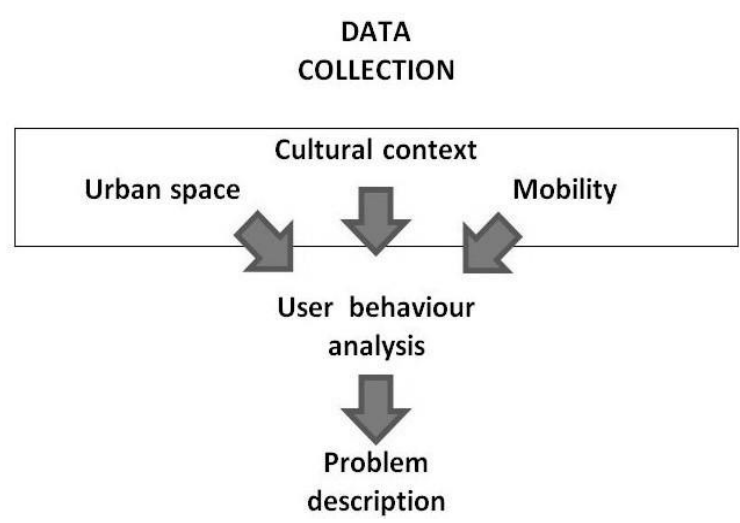

Figure 3. Framework to blogs analysis

Designers' work observation was associated with monitoring of blog posts. Results of problem and briefing are presented in Table 2.

Table 2. Problems and briefing posted at the blogs

\begin{tabular}{|c|c|c|}
\hline Teams & Problem & Brief \\
\hline $\begin{array}{c}\text { Team } \\
5\end{array}$ & $\begin{array}{l}\text { In this project, a portable and inexpensive sliding unit that allows } \\
\text { the users to slide down on snowy hills is requested }\end{array}$ & a basic checklist \\
\hline $\begin{array}{c}\text { Team } \\
6\end{array}$ & $\begin{array}{l}\text { How to pay the fare? Driver should focus on his/her driving action } \\
\text { (shouldn't distract him/her). Passengers don't need to disturb others }\end{array}$ & complete \\
\hline $\begin{array}{c}\text { Team } \\
11\end{array}$ & $\begin{array}{l}\text { How to improve the accessibility of people with reduced mobility, } \\
\text { such as wheelchair users, the elderly, pregnant women and obese } \\
\text { people in public transport }\end{array}$ & a basic checklist \\
\hline $\begin{array}{c}\text { Team } \\
12\end{array}$ & Outdoors Bicycle Rack & $\begin{array}{l}\text { complete, } \\
\text { without schedule. }\end{array}$ \\
\hline $\begin{array}{c}\text { Team } \\
14\end{array}$ & $\begin{array}{l}\text { Develop a shared transportation product/service for the elderly that } \\
\text { they can use for their everyday life. }\end{array}$ & $\begin{array}{l}\text { a basic checklist, } \\
\text { without schedule. }\end{array}$ \\
\hline $\begin{array}{c}\text { Team } \\
16\end{array}$ & $\begin{array}{l}\text { Develop a product/service for users who primarily use public } \\
\text { transportation, combining greater safety and reliability in use }\end{array}$ & $\begin{array}{l}\text { complete, } \\
\text { without schedule. }\end{array}$ \\
\hline
\end{tabular}

Note: the problem texts have been copied from the teams' original briefs

The design brief analysis took into account that this stage lasted two weeks and during this period the teams were supposed to interact to define which information should be provided by each team working as clients. The better the interaction, the more information was expected. Results suggest that the most complete interaction at that moment was between Team 12 and Team 6 (Table 3).

The Cultural context was considered only by only one team (Team 12). This result was unexpected, as design is a culture-based profession and the Global Studio aims to explore cultural issues in collaborative design. The Urban space, on the other hand, was taken into consideration by all teams, but only one of them included photos (Team 12). Mobility was considered by only four teams, all of which included both data and photos. This is an unexpected result, as the project itself was about local mobility. Finally, User behaviour appeared in the blogs of four teams. 
Table 3. Dimensions presented by each pair of teams

\begin{tabular}{|c|c|c|c|c|c|}
\hline Team & Cultural context & Urban space & Mobility & User behaviour & Team \\
\hline Team 11 & No & Data & Data and photos & Yes & \\
\hline & No & Data & No & No & Team 5 \\
\hline Team 12 & Yes & Data and photos & Data and photos & No & \\
\hline & No & Data & Data and photos & Yes & Team 6 \\
\hline Team 16 & No & Data & Data and photos & Yes & \\
\hline & No & Data & No & No & Team 14 \\
\hline
\end{tabular}

It is worth highlighting that none of the teams considered all of the four dimensions. Additionally, none of the pairs considered the same set of dimensions, suggesting that at that moment they did not share what each team should deliver. As a consequence, after the delivery of the brief design to the paired teams, many doubts emerged and information indispensable to the development of the project, which had not been presented initially, appeared in the comment spaces of the blogs.

It was noticed that the following factors affected the process: $i$. information about the local context; $i$. time zone issues; and iii. language. Problems concerning Information about the local context may be exemplified with Team 5's question to Team 11 "Should we consider that the design solution would be for buses? If it would be for buses, could you share with us further photos of them?". Difference on Time zone was as commented by Team 14 "We were trying to arrange a skype meeting but because of 11 hours difference in time it might be difficult for both of us to be awake and be on skype". Finally, problems related to Language was mentioned both by Team 14, "Because we do not have that good English skills we are not exactly sure we have given you the correct things", and Team 12, "If you encounter any errors in the translation or the information looks difficult to understand, do not be afraid to contact us for clarification, we are open for discussion always".

The initial impressions of the teams when receiving the design briefs pointed to the possibility that, when employing only the asynchronous tool of blogs, there was a strong possibility of mistaken or partial understanding of the design briefs' requirements. The difficulties of understanding, both by the client and the designer, were mitigated by the possibilities of synchronous contact, even if sometimes hampered by technical barriers such as the quality of web transmissions. During the evolution of their work, the teams were able to overcome these difficulties.

\subsection{Interviews with the Brazilian teams at the end of the project}

At the end of the project, each team was interviewed. Six questions addressed the roles of designer and client (three for each) and a closing question asked for a synthesis, in a non-textual format, of the construction stages of the briefing. Regarding their role as clients, the following questions were asked: i. "How did you start the briefing?"; ii. "Issues and points approached"; and iii. "Steps of the process". And the following questions were asked about their role as designers: $i$. "Initial impressions about the design brief"; ii. "Difficulties"; and iii. "Was a counter-brief necessary? Why?" In both cases they were asked to "Synthesise in image the steps of the process".

Team 11 and Team 12 mentioned that, when they were working as clients, they started with a brainstorming session. Alternatively, Team 16 replied that after choosing the theme by means of a brainstorming session, a photographic survey was used. All of the three teams approached problems such as accessibility (pregnant, obese, and wheelchair-bound users, and the elderly), safety, infrastructure and information (bus schedules and itineraries).

As designers, answers to questions 1 and 2 were imbricated. A partial understanding of the design brief received from their clients, potentialized by diverse cultural contexts and the lack of proficiency in English, created difficulties and demanded alternative resources to the blog, such as video conferencing or web-based conversations. Counter-briefs were not necessary, probably due to the apparent low complexity of the design briefs presented. However, questionings were necessary: Team 12 presented 13 questions in order to clarify Team 6's design brief. 


\section{FINAL CONSIDERATIONS}

The analysis of how these students elaborated the brief design was the objective of this study. Observations, document analysis and interviews were used, but since direct access to all students was not possible, documentary analysis played the main role.

Observation of the activities developed by the Brazilian teams in class suggests that strategies for the design of the brief design are associated with the participants' individual experiences. Brainstorming was used by the three teams observed. Once the idea was defined, it was expanded and contextualised, but a limited understanding of the cultural context in which the problems were inserted was observed in the design briefs. The analysis of the cultural context is divided into tangible and intangible aspects, as well as the analysis of the users themselves. From there, technical data could be presented in order to construct meaning in relation to what was produced. As a contribution, it is suggested that the brief should start with a cultural contextualisation, rather than just bringing in technical information, which has occurred in many cases.

Analysis of all teams' posts on their blogs and on their paired teams' blogs demonstrates the difficulties they had in performing their roles:

- The design briefs were mostly incomplete. Specifically, the four dimensions considered (Cultural context, Urban space, Mobility and User behaviour) were not all presented in any individual team;

- The communication skills and resources played a fundamental role in the elucidation of doubts and clarifications of the design brief;

- The understanding between the teams was enhanced by direct contact through video calls and other forms of synchronous communication, such as WhatsApp. It should be noted that blog posts operated particularly as a repository of information but did not meet the need for synchronicity;

- The difficulty that some teams reported due to English not being their native language was overcome by a collaborative attitude that allowed students to improve their language skills.

Interviews with the Brazilian teams at the end of the project addressed how they developed the design brief when performing the role of client and the role of designer. The responses confirmed the observation of the use of brainstorming for design brief creation. None of the teams presented a counterbrief, possibly because of the relatively low complexity of the subject, but the possibility of fear or insecurity stemming from a lack of contextual knowledge cannot be ruled out. There were reports of these difficulties pertaining to cultural differences, in relation to the role of designer, and of the proficiency in English and communication, in a general way. The doubts or insufficient information that emerged in the design brief were solved by questions posted on the blogs.

It was concluded that for DB creation there is a need for greater detailing of the cultural context, as well as alignment and better exploration of the dimensions that supported the theme. The survey of the problem should not have been so dependent on individualities and blogs should contain more information regarding cultural contexts. This information and criteria may be fundamental to the clarity and conciseness of the scenarios for all teams.

\section{REFERENCES}

[1] Blyth A. and Worthington J. (2010) Managing the Brief for Better Design. Taylor and Francis, USA, 2010

[2] Phillips P. (2004) Creating the perfect design brief: How to Manage Design for the Strategic Advantage. Allwent Press. New York, 2004.

[3] Hong B.B., Bohemia E., Neubauer R. and Santamaria L. (2018) Design for users: The Global Studio, In Proceedings of E\&PDE2018 the $21^{\text {th }}$ International Conference On Engineering and Product Design Education. 